Institute of Social and Economic Research, Osaka University

Opportunism and the Dynamics of Incomplete Contracts

Author(s): Mehmet Bac

Source: International Economic Review, Vol. 34, No. 3 (Aug., 1993), pp. 663-683

Published by: Wiley for the Economics Department of the University of Pennsylvania and Institute of Social and Economic Research, Osaka University

Stable URL: https://www.jstor.org/stable/2527187

Accessed: 13-02-2019 06:57 UTC

JSTOR is a not-for-profit service that helps scholars, researchers, and students discover, use, and build upon a wide range of content in a trusted digital archive. We use information technology and tools to increase productivity and facilitate new forms of scholarship. For more information about JSTOR, please contact support@jstor.org.

Your use of the JSTOR archive indicates your acceptance of the Terms \& Conditions of Use, available at https://about.jstor.org/terms

Wiley, Institute of Social and Economic Research, Osaka University are collaborating with JSTOR to digitize, preserve and extend access to International Economic Review 


\title{
OPPORTUNISM AND THE DYNAMICS OF INCOMPLETE CONTRACTS*
}

\author{
By Mehmet BAC ${ }^{1}$
}

\begin{abstract}
This paper studies a buyer-seller relationship where "quality" is not contractible but is affected by effort and the seller's privately known innate value. The seller's cost of effort is also private knowledge. Assuming constant outside opportunities, we show that more than two contracts is redundant, the sequence of contracts exhibits increasing prices and durations, and commitments for prices beyond the actual contract invite opportunism, not effort. The seller uses effort during the screening process, which improves noncontractible quality. As a result, type-related information may have negative value when contracts are incomplete.
\end{abstract}

\section{INTRODUCTION}

Economic relationships differ in many dimensions such as uncertainty, verifiability and measurement of performance/quality, the frequency of trade, and the relationship-specificity of assets. This heterogeneity of relationships defies a unified approach, as evidenced by the limited success of a vast literature using standard principal-agent models in explaining real-world contracting practices. These models assume that court ordering with respect to performance is efficacious, thus rule out attribute ambiguities and idiosyncrasies associated with the supply of a good or service. As Hart and Holmstrom (1987) note, the complex piece rate contracts of the type derived in this literature are at odds with the observed simplicity of most real-world contracts. ${ }^{2}$ Furthermore, casual observations suggest that contracts are mostly incomplete; what varies from one relationship to another is the degree of incompleteness. ${ }^{3}$ There is now a growing literature stemming from Alchian and Demsetz (1972), Williamson (1985) to Hart and Moore (1988), Farrell and Shapiro (1989) and, in a labor context, MacLeod and Malcomson (1988), focusing on institutional arrangements that emerge when complete contracts are not feasible. This paper builds on this literature.

We study a long-term buyer-seller relationship with the following three main facets: i) some important aspect of trade, called "quality" is not contractible; ii) the

* Manuscript received September 1991; revised April 1992.

${ }^{1}$ Financial support from University Laval and constructive comments from two anonymous referees are gratefully acknowledged. All remaining errors are mine.

${ }^{2}$ This feature is now widely recognized. Holmstrom and Milgrom (1987), Laffont and Tirole (1986), and McAfee and McMillan (1987) have proposed explanations of linear contracts and showed their robustness in rich agency environments.

${ }^{3}$ Examples of incomplete contracts range from academics through labor, intermediate goods and procurement to sovereign debt contracts. In all these cases parties enjoy considerable discretion over important aspects of the trade, and attempts to complete the contract with additional clauses are bound to fail without verifiability. 
seller's innate value, a quality shifting parameter, and iii) his cost of effort are both private knowledge. Variants of this set-up are used by Shapiro and Stiglitz (1985) to explain involuntary unemployment, by MacLeod and Malcomson (1988) to show how hierarchies of ranks emerge in employment relationships, and by Holmstrom (1982) and Gibbons and Murphy (1992) to investigate the provision of intertemporal managerial incentives.

Unverifiability leads to contract incompleteness, which implies scope for opportunism; the seller keeps effort (quality) as low as possible. ${ }^{4}$ As we show, however, the issue looks different when one adds multidimensional hidden information problems. Among the two dimensions of the hidden information mentioned above, the innate value has a special importance in an incomplete-contracts setting for its direct, shifting impact on unverifiable quality. Examples of innate values in the labor context range from creativity to job-related skills, ability to work in a team, and in the context of vertical relations, include a supplier's sympathetic treatment of rush orders. The importance of acquiring information of this sort is manifest in the complex selection procedures the buyers adopt. And as casual observation suggests, short-term, probationary contracts are widely used to complement these imperfect selection procedures. The second component of the seller's type, the cost of effort, is identified by a parameter measuring the convexity of effort-disutility function. Its interaction with innate value and noncontractible quality, as will be shown, has important implications on the choice of contract terms. For instance, if the duration of an initial contract is increased, sustaining a high effort to match the performance of a high innate value seller becomes unattractive for a low innate value seller, which means "good" seller types can prove their innate values with less effort. Therefore, due to its impact on the efficiency of screening, the duration of a short-term contract is instrumental (rather than parametric) for the buyer. ${ }^{5}$

Central questions addressed in this paper are: how does the duration of an incomplete contract affect the seller's effort incentives? What relation exists between the terms (prices, durations) of successive contracts? ${ }^{6}$ How many con-

${ }^{4}$ Williamson (1985) defines opportunism as self-interest seeking with guile, subsuming both hidden information and hidden action. Williamson also discusses at length why and when similar incentive problems obtain within firms as between independent firms. In our model, the potential for opportunism lies in the seller's discretion over effort, which is a direct consequence of noncontractible quality.

${ }^{5}$ Sellers of durable goods usually offer a period of use without cost and obligation to buy; for a stereo system this period may be seven days, for an oak bookcase, fifteen days (note that buying is almost equivalent to signing a long-term contract.) On the other extreme, the contract of an assistant professor on average does not extend beyond six years. The striking differences between contract lengths in these examples can partially be explained in terms of relationship-specific screening considerations: the buyer of an oak bookcase can learn the inherent quality much easier than the department can the innate value of the assistant professor. In both cases, however, basically two contracts govern the relationship and buyers make a continuation choice at some interim, prespecified date.

${ }^{6}$ The issue of contract duration per se has attracted little attention. Among few recent contributions are Harris and Holmstrom (1987) and Dye (1985). In both papers an exogenous cost of contract renegotiation (or state verification) is crucial in determining durations in a stochastic environment. We shall assume no contracting costs, however. The literature on the theory of contracts offers several explanations for the emergence of short-term contracts. We can cite prohibitive costs of writing complete long-term contracts (Hart and Moore 1988), the level of switching costs (Farrell and Shapiro 1989), incentive provision under unobservability (Townsend 1982), relationship-specificity of investment (see 
tracts should there be? How does hidden information affect the buyer's welfare when there is an unsolvable hidden action problem? ${ }^{7}$ Besides providing answers to these questions in our framework, we explore the thesis that learning about innate values plays an important role in the choice of governance structures. We show, endogenizing both the length and the number of contracts, that this learning process and the dynamic interaction between noncontractibility and two-dimensional hidden information yields contractual arrangements with an appealing simplicity. In Section 2, we describe the model and discuss simple contractual arrangements. The buyer is willing to build a trade relationship with the high innate value seller but a single long-term contract is a very poor means of achieving this goal. In order to avoid other seller types, the buyer must choose a governance structure consisting of a sequence of contracts that specify each but one price-duration pair (noncommitment.) Section 3 derives the optimal number of these contracts. In this relationship, one out of two contracts that specify the same price and leave the buyer's beliefs about the seller's innate value unchanged should be redundant. Assuming that parties use their contracting possibilities efficiently, we show that more than two contracts for the entire relationship is of no use to the buyer. For screening reasons, the buyer keeps the price of the first contract below the outside option of the seller, thus a seller type who rejects the second contract would be better-off rejecting the initial one. When seller types foresee this, a second screening (more than two contracts) becomes unnecessary.

We model the relationship as a dynamic game in Section 4. We adopt perfect Bayesian equilibrium as the solution concept, viewing the initial contract offer and continuation choices as the buyer's strategies, and the initial acceptance choice and effort levels as the seller's strategies. It is shown that prices and durations increase from one contract to the next, and the price specified in the first (respectively last) contract must be inferior (respectively superior) to the seller's outside option. In equilibrium, only the high innate value seller accepts and reveals his type at the end of the optimal first contract, and the relationship converts into a bilateral trade under perfect information. Most importantly, the first contract produces a competition between seller types. Because effort can be substituted for innate value, the seller exerts effort to convey type-related information and thereby to improve his

Crawford 1988, for example) and the information lag required to assess performance (Fudenberg, Holmstrom and Milgrom 1990). Another reason recognized for the predominance of short-term (probationary) contracting arises under hidden information and unverifiable performance: type-related and performance-relevant uncertainty should be resolved before parties settle down for a long-term contract. The treatment in this model differs from others in that the number and durations of contracts are endogenized and the seller's type is decomposed into two components.

${ }^{7}$ Generally, these questions are either irrelevant or have trivial answers in a world of complete contracts. When parties can specify all future contingencies, when all aspects of the trade are verifiable and information is perfect, a single long-term contract covering the entire planning horizon achieves efficiency. Informational problems may lead to inefficient outcomes, but mechanisms and incentive schemes are available to vitiate these hidden information and hidden action problems. These results do not extend to the case of incomplete contracts because the underlying enforcement mechanisms are absent. 
bargaining power to negotiate a favorable second contract. ${ }^{8}$ As a result, the buyer enjoys a high quality during the first contract. There is a trade-off however: a higher quality obtains at a higher price or a shorter duration. Next, in Section 5, we show that the buyer may even be better-off with respect to the case in which the seller's type is common knowledge. The potential for this somewhat surprising result lies again in contract incompleteness and the use of effort to convey type-related information.

Section 6 studies the commitment case where all contractible variables are specified in advance for the entire planning horizon, except that the buyer makes continuation choices at some interim, prespecified dates. These are long-term contracts that may encompass many periods with different durations and prices. We show that such commitments invite opportunism, not effort. Under these contracts, the seller modifies his strategy so as to systematically leave the buyer indifferent between continuation and quitting at the corresponding decision node. Section 7 concludes the paper, discusses the results and extensions.

\section{THE MODEL}

We consider a principal (buyer)-agent (seller) relationship where some aspects of the trade, say, the buyer's idiosyncratic needs, are not contractible. We loosely call these aspects "quality." The buyer consumes one unit per period of the good manufactured by the seller and trade occurs continuously in time. The buyer cares about the quality of the good $q$, and the price $p$. Her per-period utility is given by $v=q-p$. On the other hand, during his relationship with the buyer, we assume that the effort $x$ and innate value $\theta$ of the seller affect quality through the following simple technology:

$$
q(\theta, x)=\theta+x
$$

Effort is thus a substitute for innate value. Only the seller knows his twodimensional type, $\{\theta, \beta\}$, where $\theta$ represents innate value and $\beta$, a parameter measuring the convexity of the effort-disutility function. The following distributions of $\theta$ and $\beta$, however, are common knowledge:

(D1) $\theta=\theta_{H}$ with probability $\pi$, and

$$
\theta=\theta_{L} \text { with probability } 1-\pi
$$

(D2) $\beta$ is distributed on $[\underline{\beta}, \bar{\beta}]$, with continuous density function strictly positive.

There will be no loss of generality in assuming (D1) and (D2) rather than a joint distribution. ${ }^{9}$ We have $\theta_{H}>\theta_{L}$, so (A1) implies a comparative advantage for the

\footnotetext{
${ }^{8}$ A similar mechanism induces workers to choose assembly lines with high speed in Akerlof's (1976) "rat race" model. A related work, Holmstrom (1982), provides a discrete-time framework to study the relationship between managerial incentive problems and learning about ability (innate value), but leaves aside the issue of contract lengths. In his model, managers supply extra effort early in their careers to influence perceptions about their innate values. See also Gibbons and Murphy (1992).

${ }^{9}$ The correlation between $\theta$ and $\beta$ is not important for our results; it is sufficient that the distribution of $\beta$ given $\theta$ be nondegenerate.
} 


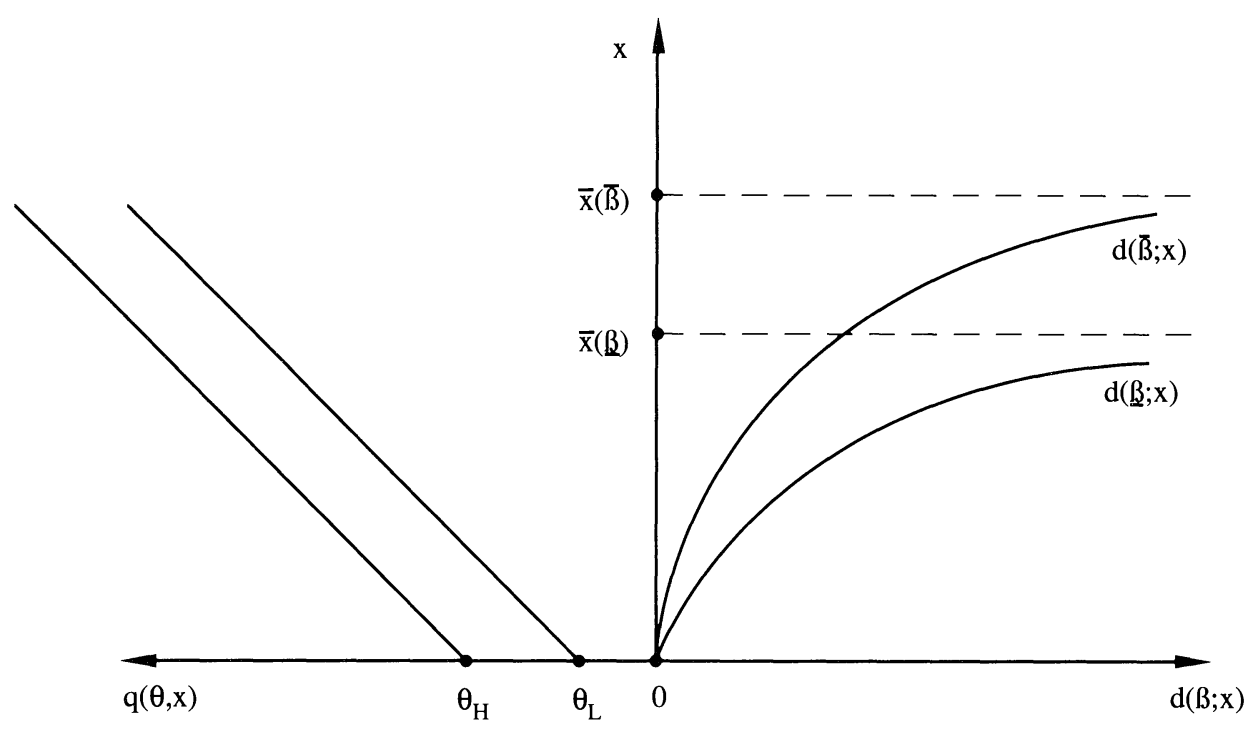

FIGURE 1

$\theta_{H}$-seller in providing quality. Following the standard assumption in principalagent theory, the per-period utility of the seller is separable in price and effort: $u=$ $p-d(\beta ; x)$. As for the disutility of effort, $d(\beta ; x)$, we assume that 10

i) $d(\beta ; x)$ is convex-increasing in $x$; and $d(\beta, 0)=0$ for all $\beta$;

ii) there exists a finite effort level, $\bar{x}(\beta)$, such that $d(\beta ; x) \rightarrow \infty$ as $x \rightarrow \bar{x}(\beta)$ and;

iii) given $\beta_{1}>\beta_{2}$, we have $\bar{x}\left(\beta_{1}\right)>\bar{x}\left(\beta_{2}\right), d\left(\beta_{1} ; x\right)<d\left(\beta_{2} ; x\right)$ and $\partial d\left(\beta_{1}\right.$; $x) / \partial x<\partial d\left(\beta_{2} ; x\right) / \partial x$ for all $x$.

(A1) is visualized on the left, (A2) on the right side of Figure 1. Given $x \in$ $[0, \bar{x}(\beta)]$, the range of $d(\beta ; x)$ is $[d(\underline{\beta}, x), d(\bar{\beta} ; x)]$. Furthermore, the disutility of effort is marginally and absolutely lower for a higher $\beta$-seller and the effort capacity $\bar{x}(\beta)$ is increasing in $\beta$. This should account for different technologies that seller types have available to improve quality. In a labor context, for example, hardworking employees would have high $\beta$-values; these would have a higher effort capacity and be able to sustain a given level of effort for a longer period (or a higher level of effort given the period.) It is therefore possible for a $\theta_{L}$-seller to outperform a $\theta_{H}$-seller provided that the latter has his $\beta$ relatively low. In the case of labor services, less talented but hardworking employees can, by exerting sufficient effort, perform better than highly talented but effort-averse employees. This interaction

${ }^{10}$ Simplicity of presentation motivates the assumptions of the model. Additivity of quality in effort and innate value, and linearity of the seller's utility in price can be dropped, and the utility function of the buyer can be replaced by $v(q, p)$, a function increasing in $q$ and decreasing in $p$. These weaker assumptions are all that is needed for Propositions 1 through 4. 
between $\theta$ and $\beta$ is an important factor behind our results on the relation between durations and prices of incomplete contracts.

Parties discount the future at the same rate $r$, and their planning horizon is infinite. So $U=E \int_{0}^{\infty} e^{-r t}[p-d(\beta ; x)] d t$ and $V=E \int_{0}^{\infty} e^{-r t}[\theta+x-p] d t$ shall denote respectively the seller's and the buyer's expected discounted utility. The seller's outside option provides the discounted utility $U^{0}$. We shall define $p$, a price which yields the seller exactly $U^{0}$ under a long-term contract, by

$$
U^{0}=\int_{0}^{\infty} e^{-r t} \underline{p} d t=\underline{p} / r .
$$

$V^{0}$ shall denote the buyer's discounted utility from her outside option. Initially, the buyer makes an incomplete, all-or-nothing contract proposal which the seller accepts or rejects. ${ }^{11}$ Prices and durations are verifiable, so acceptance turns the proposal into a contract binding only with respect to the price, duration and delivery. Because quality is not contractible, prices are ex ante independent of the quality the buyer may obtain. Consider first a single long-term contract covering the entire planning horizon. To induce participation, the price for this contract cannot be lower than $p$; nor is it profitable to increase price beyond $p$ because quality will not be affected. Hence, this contract offers $U^{0}$, leaving all types of the seller indifferent. The buyer, on the other hand, obtains

$$
V^{i}=\int_{0}^{\infty} e^{-r t}\left[\theta_{i}-\underline{p}\right] d t=\frac{\theta_{i}-\underline{p}}{r}
$$

where $i=L, H$. We shall assume $V^{L}<V^{0}<V^{H}$, so that there are no gains from trade if the seller's innate value is $\theta_{L}$. But because $V^{H}>V^{0}$, the relevant question for the buyer is how to screen the seller given the incompleteness of contracts. We shall consider two contracting modes that serve this purpose, namely, the commitment and the noncommitment case. The commitment case corresponds to longterm contracts $C^{C}=\left\{\left(p_{1}, T_{1}\right) ;\left(p_{2}, T_{2}\right) ; \ldots\right\}$, meaning that the parties agree in advance on that the price $p_{1}$ will prevail until date $T_{1}, p_{2}$ between $T_{1}$ and $T_{1}+T_{2}$, and so on. In the noncommitment case, however, the contract specifies only the actual price-duration pair, i.e., no commitment is ever made for prices and durations beyond the termination date of the actual contract. The relationship is therefore carried through a sequence of contracts, $C_{i}=\left\{p_{i}, T_{i}\right\}$. Even though future contract terms are not explicitly spelled out in the noncommitment case, parties can infer what future contracts will specify as a function of the situation prevailing at the time those contracts will be made explicit. Revelation of type-information will play an important role in this process.

The relationship as governed by a sequence of contracts can be viewed as a dynamic game. Following the announcement of a price-duration pair $\left\{p_{1}, T_{1}\right\}$, the seller makes an acceptance choice. In the affirmative, the relationship begins and

11 We assign the initial bargaining power to the buyer who faces may seller types in the agent form of the game. We shall, however, drop this assumption and allow the parties to share the surplus through negotiations as contracts expire. 
the parties are locked-in until date $T_{1}$ unless there is a mutual consent to invalidate the contract. The buyer observes quality and updates her beliefs $\mu_{1}\left(\theta_{H} \mid q_{1}\right)$ about her trading partner's innate value. Parties then negotiate a second contract $\left\{p_{2}\right.$, $\left.T_{2}\right\}$. This process is repeated from one contract to the next, as a result of which we obtain a sequence of posteriors $\left\{\mu_{1}, \mu_{2}, \ldots, \mu_{i}, \ldots\right\}$. We can now state the buyer's problem at date $t=0$.

$$
\max _{\left\{p_{1}, T_{1}\right\}} E\left\{\int_{0}^{T_{1}} e^{-r t}\left[\theta+x-p_{1}\right] d t+e^{-r T_{1}} V\left(\mu_{1}\right)\right\}
$$

subject to

$$
\begin{gathered}
U^{0} \geq \frac{1-e^{-r T_{1}}}{r} p_{1}+\frac{e^{-r T_{1}}}{r} \underline{p}, \\
U^{0} \leq \frac{1-e^{-r T_{1}}}{r}\left[p_{1}-d\left(\beta ; x^{*}\right)\right]+e^{-r T_{1}} U\left(T_{1}\right) .
\end{gathered}
$$

In (3), $V\left(\mu_{1}\right)$ represents the buyer's maximum discounted welfare as viewed from date $T_{1}$. The terms of the first contract, $\left\{p_{1}, T_{1}\right\}$, must restrict the access to "bad" seller types (especially $\theta_{L}$-sellers) who would exert no effort and take along a net benefit from the relationship. The discounted utility accruing to these types from accepting the first contract should not exceed their outside opportunity, which is stated in (4). Using (1), it simplifies to

$$
p_{1} \leq \underline{p} .
$$

(5) is a participation constraint where $U\left(T_{1}\right)$ denotes the expected utility of "good" seller types, discounted to date $T_{1}$. These seller types possibly exert a positive level of effort $x^{*}$ to signal their innate value, and the relationship must provide them an expected discounted utility at least as high as $U^{0}$. The buyer's problem as stated in (3), (4) and (5) is not well-defined because $V\left(\mu_{1}\right)$ and $U\left(T_{1}\right)$ are not specified explicitly. To overcome this problem, we must determine the number and the expected terms of future contracts.

\section{THE NUMBER OF CONTRACTS}

Except for few recent contributions explaining contract lengths through costly state verifications (e.g., Harris and Holmstrom 1987 and Dye 1985), just how long contracts should be remains an open question. Even less is known on just how many contracts should govern a given long-term relationship. We endogenize both the length (Section 4) and the number of contracts.

Along with noncontractibility of quality, the relevant determinant of the number of contracts in this paper is the resolution of type-uncertainty or, learning. Generally, when the relationship is governed by $n$ sequential contracts, $C_{1}, \ldots$, $C_{i}, \ldots, C_{n}$, we shall qualify as redundant one out of two contracts, $C_{i}$ and $C_{i+1}$, if the same price is specified in $C_{i}$ and $C_{i+1}$, and if the buyer's beliefs remain 
unchanged as $C_{i}$ expires. Proposition 1 below shows that more than two contracts for the entire relationship is of no use to the buyer.

Proposition 1. Consider the relationship as governed by $n$ contracts, each determined through negotiations once the preceding contract expires, except that the buyer specifies the first. If the buyer seeks only the seller with the highest innate value, $n-2$ contracts are redundant.

Proof. Let these contracts be labelled according to their chronological order, their durations be $T_{1}, T_{2}, \ldots, T_{n-1}, \infty$ and $p_{1}, p_{2}, \ldots, p_{n}$, the corresponding prices. Denote the buyer's beliefs at dates $T_{1}, T_{1}+T_{2}, \ldots$, by $\mu_{1}, \mu_{2}, \ldots$, respectively. As there is no external uncertainty, we must have $\mu_{1} \leq \mu_{2}$ $\leq \cdots \leq \mu_{n-1} \leq 1$ under Bayesian updating; otherwise these contracts cannot be optimal (ruled out by sequential rationality.) Consider now the first two contracts. $\mu_{1} \leq \mu_{2}$ implies that there are types who accept the first but not the second contract, i.e., some seller types leave the relationship at date $T_{1}$ for their outside option where the equivalent price is $p$. Now recall $\left(4^{\prime}\right): p_{1} \leq p$. This implies that the types who quit the buyer at date $T_{1}$ would be better-off rejecting the first contract. The rationality hypothesis eliminates these seller types and we come to the conclusion that $\mu_{1}=\mu_{2}$. Initially then, the buyer can offer a combination of the first and the second contract, the duration of this new contract would be $T_{1}+T_{2}$, and the price, some linear combination of $p_{1}$ and $p_{2}$ but lower than $\underline{p}$. This eliminates one contract. Carrying this reasoning one step further, we must have $\mu_{2}=\mu_{3}$ for the same reasons why $\mu_{1}=\mu_{2}$, which eliminates another contract. Apply the same logic inductively until the $n$th contract. This will eliminate $n-2$ contracts, leaving us with two.

Q.E.D.

Under an optimal sequence of contracts, the participation constraint of the seller selected for the last contract must be binding. Therefore all types eliminated by a second screening would do better rejecting the first contract; doing so, they would obtain $U^{0}$ and avoid the welfare loss $\left[\left(1-e^{-r T_{1}}\right) / r\right]\left(p-p_{1}\right)$. This is the essential factor that restricts the number of contracts..$^{12}$

Redundancy of more than two contracts may seem counter-intuitive. There is no commitment for the terms of future contracts, so why should not the buyer attempt a second screening? Paradoxically, it is this lack of commitment that restricts her choice at the renewal date. Initially, the low innate value seller will foresee the buyer's incentive for a second screening if $\mu_{1}$ is low, and make no mistake; he will

12 Proposition 1 holds under $n$ possible innate values provided that the buyer seeks only the seller with the highest innate value. It also holds under two-sided incomplete information, more precisely, if we allow for many buyer types who differ in the utility they derive from quality. If each buyer type prefers more quality to less, all would seek the $\theta_{H}$-seller. The screening process is not affected, thus the result in Proposition 1 holds. The case of interest is, of course, a more general one in which a long-term relationship with $m$ out of $n$ possible innate values provides the buyer a welfare higher than $V^{0}$. Although a sequence of two contracts for the entire relationship is again feasible, we have no results proving its optimality from the buyer's perspective. Deriving the optimal number of contracts with endogenous lengths and prices for this general case seems to be a formidable task, beyond the scope of this paper. See, however, Section 7 where we also discuss the use of contracts to achieve a matching between buyer and seller types. 


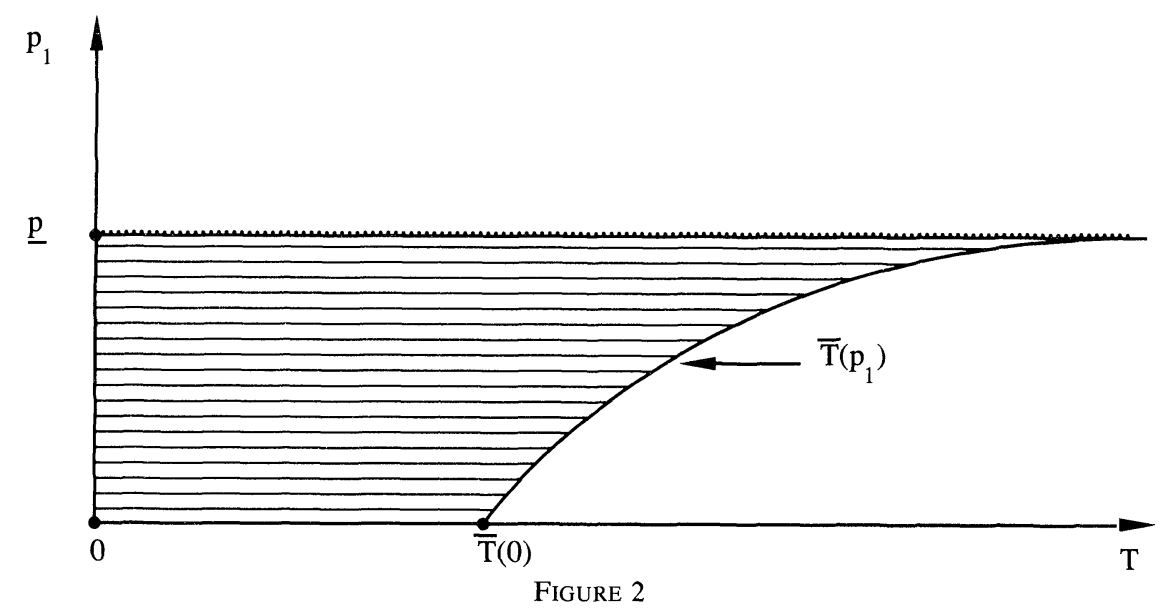

reject the first contract. Almost all type-related information should therefore be revealed during the first contract, that is, we should expect $\mu_{1} \approx 1$ in equilibrium. This result, and the underlying interaction between seller-types are made precise in Section 4.2 .

\section{NONCOMMITMENT}

The relationship will be governed by two contracts; $p_{1}$ and $T$ shall denote respectively the price and the duration of the first contract, and $p_{2}$, the price that shall be negotiated at date $T$ for the remaining of the relationship if the seller convinces the buyer for continuation. The buyer's objective is given in (3) where $V\left(\mu_{1}\right)=\left[\mu_{1} \theta_{H}+\left(1-\mu_{1}\right) \theta_{L}-p_{2}\right] / r$, and the two constraints to her problem are $\left(4^{\prime}\right)$ and

$$
U^{0} \leq \frac{1-e^{-r T}}{r}\left[p_{1}-d\left(\beta ; x^{*}\right)\right]+\frac{e^{-r T}}{r} p_{2} .
$$

To characterize the set of pairs $\left\{p_{1}, T\right\}$ that satisfy $\left(5^{\prime}\right)$, it is useful to define the boundary of this set, $\bar{T}\left(p_{1}\right)$, given an expected price $p_{2}$ for the next contract. Hence, for each $p_{1} \leq p$, the maximum duration that makes $\left(5^{\prime}\right)$ binding (this corresponds to $x^{*}=0$ ) yields the $\bar{T}\left(p_{1}\right)$ locus:

$$
\bar{T}\left(p_{1}\right)=(1 / r) \ln \left\{\left(p_{2}-p_{1}\right) /\left(\underline{p}-p_{1}\right)\right\} .
$$

(6) is well-defined only if $p_{2}>p$. Combined with (4'), it yields the dynamics of prices: $p_{1} \leq p<p_{2}$. Since the seller "suffers" during the screening process (the first contract,) he must somehow expect a compensation, which explains why $p<$ $p_{2}$. From (6), we have $\bar{T}\left(p_{1}\right) \rightarrow \infty$ as $p_{1} \rightarrow p$ from below, and for $p_{1}=0$, it follows that the maximum duration of the first contract is $\bar{T}(0)=(1 / r) \ln \left\{p_{2} / p\right\}$. The pairs $\left\{p_{1}, T\right\}$ that satisfy $\left(4^{\prime}\right)$ and $\left(5^{\prime}\right)$ are depicted in Figure 2 by the shaded area.

The strategy set of each seller type consists of a binary application choice $(a=$ 
1 for acceptance and $a=0$ for rejection) and of a choice of effort $x \in[0, \bar{x}(\beta)]$ which affects quality through (A1). So given $\left\{p_{1}, T\right\}$, the objective of the seller if he accepts the contract is

$$
\max _{x} E\left\{\int_{0}^{T} e^{-r t}\left[p_{1}-d(\beta ; x)\right] d t+e^{-r T} U(T)\right\}
$$

given the application choices and effort strategies of all other seller types.

Note that $U(T)$ depends on the buyer's decision on whether to keep the seller $(b=1)$ or not $(b=0)$, and in the affirmative, on the negotiated price $p_{2}$. We have $U(T)=p_{2} / r$ if $b=1$, and $U(T)=U^{0}$ otherwise. The strategies mentioned above must form a perfect Bayesian equilibrium, thus sequential rationality given beliefs, and that beliefs be obtained wherever possible using Bayes' rule is required. To summarize,

(E1) $b$ is optimal for the buyer given her beliefs $\mu\left(\theta_{H} \mid q\right)$ and $p_{2}$;

(E2) $\{a, x\}$ is optimal for the seller given $\left\{p_{1}, T\right\}$ and the fact that the buyer's decision $b$ will depend on quality;

(E3) $\left\{p_{1}, T\right\}$ is optimal for the buyer given subsequent strategies; and

(E4) the buyer uses Bayes' rule to derive $\mu\left(\theta_{H} \mid q\right)$ from her prior and the quality she has been observing.

We have omitted the arguments in the strategies in (E1) through (E4) for conciseness. Note that in equilibrium, the strategies for the first contract may affect the negotiated terms of the second contract only through the posterior $\mu$. On the other hand, (E1) requires the buyer to choose $b$ given her posterior beliefs, even off the equilibrium path. In the spirit of the backward solution technique, we can now proceed to the contract renewal stage and discuss the determination of $p_{2}$ and $b$ taking the buyer's posterior as given.

4.1. Negotiation for the Second Contract. Type-related information signaled during the first contract determines, through the buyer's updated beliefs, whether the relationship should extend to a second contract. Given $U^{0}$ and $V^{0}$, the parties' disagreement utilities, a critical $\mu^{c}>\pi$ can be defined by $V\left(p, \mu^{c}\right)=V^{0}$, such that the net expected gains from the continuation of the relationship are strictly positive when $\mu \in\left(\mu^{c}, 1\right]$. The buyer sets $b=0$ and chooses her outside option if $\mu<\mu^{c}$. We shall impose no restriction on the outcome of the negotiations for the case $\mu>\mu^{c}$. Qualitatively, our results are independent of the bargaining scheme that parties choose to divide the pie provided that the seller obtains a share however small. All that matters is that the parties implicitly know or anticipate how the outcome of the negotiations $\left(p_{2}(\mu)\right)$ will vary as a function of the situation $(\mu)$ at date $T$. For any $p_{2}^{*}>p$ that emerges as a bargaining outcome, one can verify that there exists a set of pairs $\left\{p_{1}, T\right\}$ that satisfy $\left(4^{\prime}\right)$ and $\left(5^{\prime}\right)$ though this set gets smaller as $p_{2}^{*} \rightarrow p$. The price $p_{2}^{*}(1)$ that comes across the bargain when the seller proves $\theta_{H}$ is of particular interest for the following sections.

4.2. Continuation Equilibrium. Let $\left\{p_{1}, T\right\}$ be an arbitrary contract proposal that satisfies $\left(4^{\prime}\right)$ and $\left(5^{\prime}\right)$. We define a continuation equilibrium as a strategy set and 
an updating rule by (E1), (E2) and (E4), given the contract proposal $\left\{p_{1}, T\right\}$. Denoting by $q^{*}$ the equilibrium level of quality, we specify off the equilibrium path beliefs by: $\mu=1$ if $q>q^{*}$ and $\mu=\pi$ if $q<q^{*}$. Last, by (8) we define $x_{\theta_{L}}^{M}(\bar{\beta})$, the maximum effort that makes the $\left\{\theta_{L}, \bar{\beta}\right\}$-seller indifferent between accepting and rejecting the contract provided this convinces the buyer that $\theta=\theta_{H}$ :

$$
\left(1-e^{-r T}\right)\left[p_{1}-d\left(\bar{\beta} ; x_{\theta_{L}}^{M}(\bar{\beta})\right)\right]+e^{-r T} p_{2}^{*}(1)=\underline{p} .
$$

The behavior of the least effort-averse type of a $\theta_{L}$-seller (the $\left\{\theta_{L}, \bar{\beta}\right\}$-seller) will be critical for $\theta_{H}$-sellers in determining effort strategies. The following proposition characterizes continuation equilibria.

Proposition 2. Given any $\left\{p_{1}, T\right\}$ satisfying (4') and (5') and a bargaining outcome that determines $p_{2}$, there exists a unique continuation equilibrium in which the seller accepts only if he is $\theta_{H}$. This continuation equilibrium has the following properties:

i) $\mu^{*}=1$ and the buyer sets $b^{*}=1$ as the first contract expires;

ii) the $\theta_{H^{-}}$-sellers set $a^{*}=1$ and exert all the same effort level $x_{\theta_{H}}^{*}=\max \{0$, $x_{\theta_{L}}^{M}(\bar{\beta})-\left(\theta_{H}-\theta_{L}\right)$;

iii) all $\theta_{\underline{L}}$-sellers set $a^{*}=0$ with the exception of the $\left\{\theta_{L}, \bar{\beta}\right\}$-seller who, if $x_{\theta_{L}}^{M}(\bar{\beta})-\left(\theta_{H}-\theta_{L}\right)>0$, is indifferent between $a^{*}=0$ and $a^{*}=1$ with exerting the effort $x_{\theta_{L}}^{M}(\bar{\beta})$.

PROOF. We first verify that the strategies described in the proposition form a continuation equilibrium. Given $\mu^{*}=1, b^{*}=1$ is clearly optimal for the buyer since $V\left(p_{2}^{*}(1), 1\right)>V^{0}$. On the other hand, setting $a^{*}=0$ is optimal for all $\theta_{L}$-sellers whose $\beta<\bar{\beta}$, because given the buyer's posterior and strategy, we have

$$
\left(1-e^{-r T}\right)\left[p_{1}-d\left(\beta ; x_{\theta_{L}}^{M}(\bar{\beta})\right)\right]+e^{-r T} p_{2}^{*}(1)<\underline{p} .
$$

The above inequality holds also for the $\left\{\theta_{L}, \bar{\beta}\right\}$-seller if $x_{\theta_{L}}^{M}(\bar{\beta})<\theta_{H}-\theta_{L}$. Now if $x_{\theta_{L}}^{M}(\bar{\beta})>\theta_{H}-\theta_{L}$, the $\theta_{H}$-sellers' optimal strategy consists of $a^{*}=1$ and choosing $x_{\theta_{H}}^{*}=x_{\theta_{L}}^{M}(\bar{\beta})-\left(\theta_{H}-\theta_{L}\right)$. Deviating from the strategy $\left\{a^{*}=1, x_{\theta_{H}}^{*}\right\}$ only decreases their utility given the strategies of all other types and the buyer's beliefs off the equilibrium path. Since only $\theta_{H}$-sellers choose $a^{*}=1$, the buyer's continuation choice $b^{*}=1$ and the posterior $\mu^{*}=1$ are justified.

Given $\left\{p_{1}, T\right\}, x_{\theta_{L}}^{M}(\bar{\beta})$ as defined by (8) and $x_{\theta_{H}}^{*}=\max \left\{0, x_{\theta_{L}}^{M}(\bar{\beta})-\left(\theta_{H}-\theta_{L}\right)\right\}$ are clearly unique. Combined with the buyer's continuation choice and the sellers' acceptance choices, the continuation equilibrium so obtained is also unique.

Q.E.D.

The intuition for Proposition 2 can be grasped from Figures 3 and 4 . The contract $\left\{p_{1}, T\right\}$ determines, through (8), the maximum effort the $\left\{\theta_{L}, \bar{\beta}\right\}$-seller can exert to imitate a $\theta_{H}$-seller. If this effort falls short of the quality gap $\theta_{H}-\theta_{L}$, then the $\theta_{H}$-seller chooses $x_{\theta_{H}}^{*}=0$ owing to his comparative advantage. For an initial contract to produce this type of continuation equilibrium, it must specify a low price and/or a high duration. Figure 4 visualizes these contracts by region-I, and the 


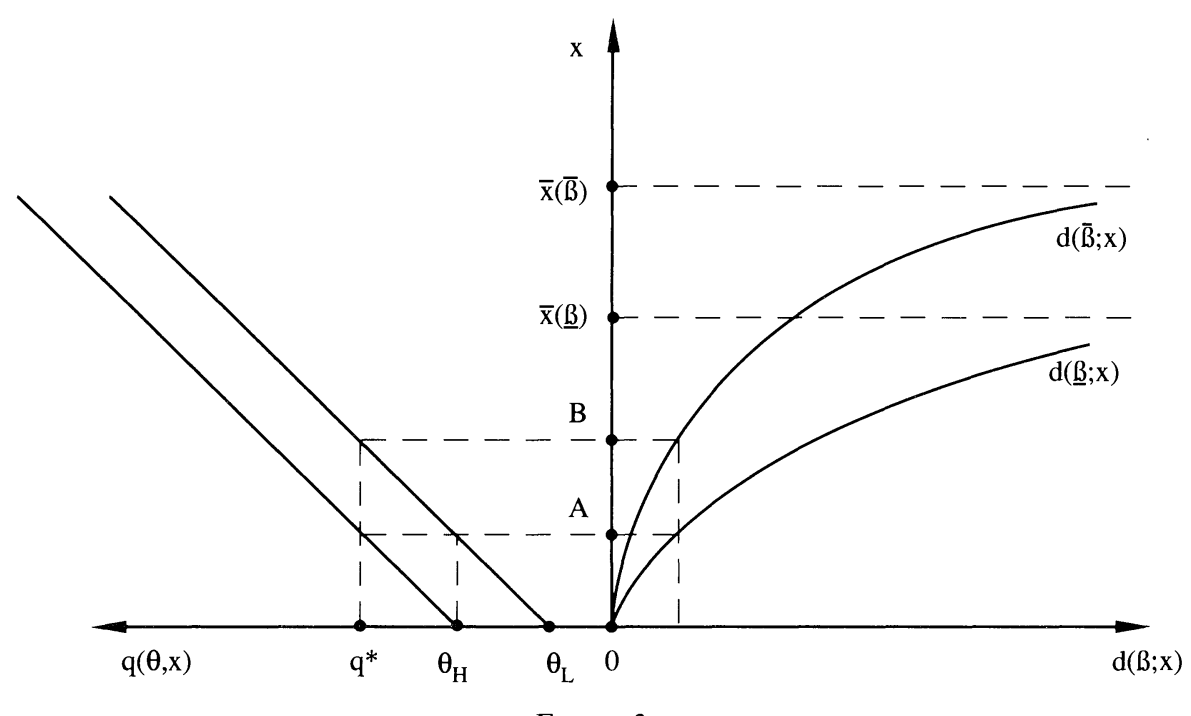

FIGURE 3

corresponding maximum effort induced on the $\left\{\theta_{L}, \bar{\beta}\right\}$-seller falls into the interval $[0, A)$ in Figure 3. We remark that all pairs $\left\{p_{1}, T\right\}$ that lie in region-I of Figure 4 are dominated by the $\bar{T}\left(p_{1}\right)$ locus, defined earlier in (6) as the maximum duration that a $\theta_{H}$-seller would accept as a function of $p_{1}$. Since quality is not affected and $p_{1}<p_{2}$, the buyer would enhance her welfare by increasing the duration until $T=$ $\bar{T}\left(p_{1}\right)$. Her discounted welfare along the $\bar{T}\left(p_{1}\right)$ locus is constant and, using (6) in (3), equal to $\left(\theta_{H}-p\right) / r$. It is interesting that this welfare is just equal to the welfare the buyer would enjoy if her facing a $\theta_{H}$-seller were initially common knowledge. ${ }^{13}$

Region-II is the northwestern neighbor of region-I in Figure 4. Along the frontier between these two regions, $T^{1}\left(p_{1}\right)$, we have $x_{\theta_{H}}^{*}=0$ and (8) holds for $x_{\theta_{L}}^{M}(\bar{\beta})=$ $\theta_{H}-\theta_{L}$. Here, $\theta_{H}$-sellers choose $x_{\theta_{H}}^{*}=0$, and the $\left\{\theta_{L}, \bar{\beta}\right\}$-seller is indifferent between $a^{*}=0$ and exerting $x_{\theta_{L}}^{M}(\bar{\beta})$, an effort just enough to fill the quality gap $\theta_{H}-\theta_{L}$. This corresponds to point $\mathrm{A}$ in Figure 3. If, starting from the $T^{I}\left(p_{1}\right)$ locus, $p_{1}$ is increased and/or $T$ is decreased, all $\theta_{H}$-sellers regardless of their $\beta$, supply a positive effort given by $x_{\theta_{H}}^{*}=x_{\theta_{L}}^{M}(\bar{\beta})-\left(\theta_{H}-\theta_{L}\right)$. For if they don't, they risk being outperformed by $\theta_{L}$-sellers.

Finally, region-III in Figure 4 is associated with the highest effort levels and quality (but, as we shall show, high quality is not costless to obtain). Competition between $\theta_{H}$ and $\theta_{L}$-sellers is so strong that even some effort averse $\theta_{H}$-sellers (those who have lower $\beta \mathrm{s}$ ) reject the contract at the outset. The frontier between region-II and III, $T^{11}\left(p_{1}\right)$ in Figure 4 , is characterized by the following two conditions: i) the $\left\{\theta_{L}, \bar{\beta}\right)$-seller is indifferent between $a^{*}=0$ and exerting $x_{\theta_{L}}^{M}(\bar{\beta})$, ii) the $\left\{\theta_{H}, \underline{\beta}\right\}$-seller is indifferent between $a^{*}=0$ and exerting $x_{\theta_{H}}^{*}=x_{\theta_{L}}^{M}(\bar{\beta})-$ $\left(\theta_{H}-\theta_{L}\right)$. The value of $x_{\theta_{L}}^{M}(\bar{\beta})$ corresponding to this equilibrium is represented by point $\mathrm{B}$, and the resulting quality, by $q^{*}$ in Figure 3. As $p_{1}$ is increased and/or $T$ is

\footnotetext{
13 The value of type related information is discussed later in Section 5 .
} 


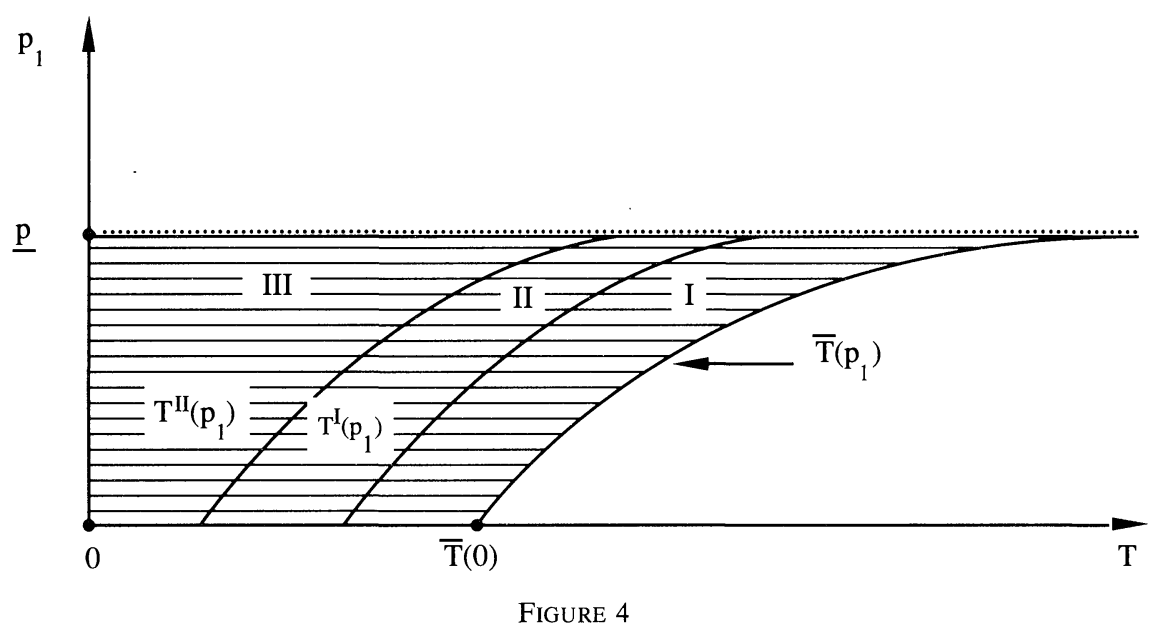

decreased further, the pressure coming from the $\left\{\theta_{L}, \bar{\beta}\right\}$-seller eliminates the low- $\beta$ types of $\theta_{H}$-sellers. From the foregoing discussion we conclude the following.

PROPOSITION 3. The buyer obtains a quality $q^{*} \geq \theta_{H}$ in any continuation equilibrium. Except in region-I where $q^{*}=\theta_{H}$ is constant, quality is increasing in $p_{1}$ and decreasing in $T$.

Proof. $\quad q^{*} \geq \theta_{H}$ is immediate from Proposition 2 because $\mu^{*}=1$. For the rest of the proof, suffice it to show that $x_{\theta_{L}}^{M}(\bar{\beta})$ is increasing in $p_{1}$ and decreasing in $T$ (because $q^{*}=\theta_{L}+x_{\theta_{L}}^{M}(\bar{\beta})$ and $x_{\theta_{L}}^{*}(\bar{\beta})=x_{\theta_{L}}^{M}(\bar{\beta})$ except in region-I). Rearranging (8), we obtain

$$
d\left(\bar{\beta} ; x_{\theta_{L}}^{M}(\bar{\beta})\right)=p_{1}-\frac{p-e^{-r T} p_{2}^{*}(1)}{1-e^{-r T}} .
$$

Denoting the inverse of $d(\bar{\beta} ; x)$ with respect to $x$ by $\phi(\bar{\beta} ; d)$, we can solve for

$$
x_{\theta_{L}}^{M}(\bar{\beta})=\phi\left(\bar{\beta} ; p_{1}-\frac{p-e^{-r T} p_{2}^{*}(1)}{1-e^{-r T}}\right) .
$$

$\phi(\bar{\beta} ; d)$ is concave-increasing in $d$. Using the expression above, it is easy to verify that $x_{\theta_{L}}^{M}(\bar{\beta})$ is increasing in $p_{1}$ and decreasing in $T$.

Q.E.D.

The dependence of quality on the price and the duration of the first contract as given in Proposition 3 is generated by the competition for the second contract. Since the $\theta_{H}$-seller is able to negotiate a price higher than $p$ for the second contract, increasing $p_{1}$ or decreasing $T$ induces the $\theta_{H}$-seller to increase effort and quality in order to outperform the $\theta_{L}$-seller.

4.3. The Optimal First Contract. The buyer's objective is naturally to obtain the highest possible quality as cheap as possible for the longest period of time, but 
Proposition 3 stipulates that these goals are in conflict. The optimal first contract $\left\{p_{1}^{*}, T^{*}\right\}$ balances these effects.

Let $q^{*}\left(p_{1}, T\right)$ denote the continuation equilibrium quality generated by the contract $\left\{p_{1}, T\right\}$. According to (E3) and our analysis of the continuation equilibrium, $\left\{p_{1}^{*}, T^{*}\right\}$ will be the buyer's perfect Bayesian equilibrium strategy if

$$
\left\{p_{1}^{*}, T^{*}\right\} \in \underset{p_{1}, T}{\operatorname{argmax}}\left\{\frac{\left(1-e^{-r T}\right)}{r}\left[q^{*}\left(p_{1}, T\right)-p_{1}\right]+e^{-r T} \frac{p_{2}^{*}(1)}{r}\right\} .
$$

It is useful to characterize the two necessary conditions for an interior solution. The first is given by: $\partial q^{*} / \partial p_{1}=1$, or using $q^{*}=\theta_{L}+x_{\theta_{L}}^{M}(\bar{\beta})$ and (9),

$$
\phi^{\prime}(\bar{\beta} ; d)=1
$$

where $\phi^{\prime}(\bar{\beta} ; d)$ denotes the partial derivative of $\phi$ with respect to its second argument. The second necessary condition is

$$
e^{-r T}\left[\left(q^{*}-\theta_{H}\right)+\left(p_{2}^{*}(1)-p_{1}\right)\right]+\left[\frac{\left(1-e^{-r T}\right)}{r}\right] \frac{\partial q^{*}\left(p_{1}, T\right)}{\partial T}=0 .
$$

Using (9) and $q^{*}=\theta_{L}+x_{\theta_{L}}^{M}(\bar{\beta})$, this condition can be written as

$$
\left(q^{*}-\theta_{H}\right)+\left(p_{2}^{*}(1)-p_{1}\right)-\frac{\left(p_{2}^{*}(1)-\underline{p}\right)}{1-e^{-r T}} \phi^{\prime}(\bar{\beta} ; d)=0 .
$$

(10) balances the effect of a marginal increase in $p_{1}$, and (11), of a marginal increase in $T$ on quality. The third term in (11) represents the cost incurred as a quality deterioration due to the weakened competition between seller types, whereas the first two terms, the benefit arising from increasing the duration at constant quality $q^{*}$. As expected, the design of the optimal contract depends critically on the curvature of $d(\beta ; x)$. There are two broad classes of possible outcomes.

Proposition 4. The set of perfect Bayesian equilibrium strategies $\left\{p_{1}^{*}, T^{*}\right\}$ for the buyer lies either on the $\bar{T}\left(p_{1}\right)$ locus, or in region-II or III. In the latter case, the optimal first contract satisfies (10) and (11).

Proof. We have previously shown that any $\left\{p_{1}, T\right\}$ that lies in region-I is dominated by the $\bar{T}\left(p_{1}\right)$ locus. What remains to show is the existence of a nontrivial optimal contract $\left\{p_{1}^{*}, T^{*}\right\}$ (perfect Bayesian equilibrium strategy) that falls into region-II or III when (10) and (11) hold. To be well-defined, this contract must satisfy $p_{1}^{*} \leq p$ and $T^{*}>0$. The first is already implied by $\left(4^{\prime}\right)$. As for $T^{*}>$ 0 , note that for any $p_{1}^{*}$ satisfying $(10)$, i.e., $\phi^{\prime}(\bar{\beta} ; \cdot)=1$, (11) becomes positive as $T \rightarrow 0$ (which means $T$ should be increased.) Thus $T^{*}=0$ cannot be optimal and $\left\{p_{1}^{*}, T^{*}\right\}$ must satisfy (10) and (11) if it lies in region-II or III. $\quad$ Q.E.D.

$\left\{p_{1}^{*}, T^{*}\right\}$ will lie on the $\bar{T}\left(p_{1}\right)$ locus when quality is rather insensitive to the price and/or duration of the first contract. This is equivalent to saying that the two instruments, $p_{1} 2$ and $T$, are too costly to induce additional effort. When $T$ is short, 
the effort $x_{\theta_{L}}^{M}(\bar{\beta})$ that the $\left\{\theta_{L}, \bar{\beta}\right\}$-seller is willing to exert is relatively high (this should be clear from (8)), so decreasing $T$ induces very little additional effort in contrast to when $T$ is high (and $x_{\theta_{L}}^{M}(\bar{\beta})$ is low). For this reason, $T^{*}$ is always positive and finite. On the other hand, since $x_{\theta_{L}}^{M}(\bar{\beta})=\theta_{H}-\theta_{L}$ along $T^{I}\left(p_{1}\right)$, the likelihood of the case $\left\{p_{1}^{*}, T^{*}\right\} \in \bar{T}\left(p_{1}\right)$ increases with $\theta_{H}-\theta_{L}$, the difference between the potential innate values of seller-types. This is quite intuitive: a seller who enjoys a big innate advantage can signal his innate value with less or even no effort because competition from other types is weak.

We close this section with a discussion on the efficiency of equilibrium efforts. Since quality is not contractible, there is no direct link between efforts and prices. Therefore, the inefficiency of the equilibrium described in this section should not be surprising. Prices rather serve screening purposes, and effort, if any, comes about as a by-product of this process. Consider an equilibrium with positive effort. The $\left\{\theta_{L}, \bar{\beta}\right\}$-seller's effort $\left(x_{\theta_{L}}^{M}(\bar{\beta})\right)$ is efficient because (10) holds; but this seller is indifferent between accepting and rejecting the proposed contract. On the other hand, all $\theta_{H}$-sellers provide the same quality, but because their cost of effort depends on their $\beta$, those who have higher $\beta$ s suffer less (provide the same quality with less effort). From this feature of the equilibrium, we can see whether the $\theta_{H}$-seller's effort is excessive or not as a function of his $\beta$, the price $p_{1}$ and the duration $T$. Clearly, the $\left\{\theta_{H}, \bar{\beta}\right\}$-seller's effort is less than efficient because, although he has the same effort-disutility function as the $\left\{\theta_{L}, \bar{\beta}\right\}$-seller, he enjoys a high innate value. He can thus signal his innate value with an effort lesser than $x_{\theta_{L}}^{M}(\bar{\beta})$, the efficient effort for the effort-disutility function of the type $\bar{\beta}$. On the other hand, the $\left\{\theta_{H}, \beta\right\}$-seller's effort may be excessive, that is, his marginal cost of effort may exceed the marginal value of the quality produced. Generally, the most effort-averse types of the $\theta_{H}$-seller will exert excessive efforts for high values of $p_{1}$ and/or short durations. This will indeed be the case if the contract lies on the $T^{I I}\left(p_{1}\right)$ locus in Figure 4. As explained in Section 4.2 , both the $\left\{\theta_{L}, \bar{\beta}\right\}$ and $\left\{\theta_{H}, \beta\right\}$-sellers are indifferent between accepting and rejecting a contract on the $T^{I I}\left(p_{1}\right)$ locus. Given that the indifference condition holds for both seller types, the absolute effort disutility of the two must be equal. For this contract, we know that the $\left\{\theta_{L}, \bar{\beta}\right\}$-seller's effort is efficient. But by (A2), the marginal cost of effort for the $\left\{\theta_{H}, \beta\right\}$-seller is necessarily higher than the $\left\{\theta_{L}, \bar{\beta}\right\}$-seller at the same level of effort disutility, which implies that the $\left\{\theta_{H}, \beta\right\}$-seller (and other most effort-averse types) exerts an excessive effort if the initial contract lies on the $T^{11}\left(p_{1}\right)$ locus.

\section{THE VALUE OF TYPE-RELATED INFORMATION}

To sum up and sharpen the results presented so far: when noncontractible quality is affected by effort and the seller's innate value, a sequence of two contracts allows the buyer to use the duration of the initial contract, in conjunction with price, as a device to screen the $\theta_{H}$-seller. The latter signs the initial contract for a price lower than his outside option, anticipating the high price he will later be able to negotiate with the buyer, when the relationship converts into a bilateral trade under perfect information. As a consequence of the competition between seller types during the initial contract, the $\theta_{H}$-seller may use effort if necessary. This phenomenon 
manifests itself in many relationships. For example, employees do their best during probationary contracts to convey various type-related information (such as ability to work in a team, discipline, creativeness, etc.) and the by-product of the effort used in this process is a high performance, which clearly benefits employers. Another example perhaps closer to the reader is assistant professors' efforts to signal research and teaching abilities, and thereby avoid being denied tenure. The department enjoys both type-related information and high productivity. In vertical relations, the supplier of a specific input puts much effort to convince the buyer that the inherent quality of the input is high and thereby to obtain an increase in volume/price of future orders. In all these cases, the increase in the buyer's welfare is closely linked to the twofold role of effort: transmission of information and improvement of "quality." One is then led to ask whether the value of information about the seller's type is nonpositive in an incomplete-contracts setting; more precisely, whether the buyer would be worse-off if types were common knowledge.

The two parties can never reach the first-best outcome when quality is not contractible, regardless of the buyer's information about the seller's type. The buyer is exposed to the seller's opportunism. However, since the seller never needs exerting effort when his type is known, quality is strictly higher under hidden information if the corresponding equilibrium exhibits a positive effort level.

Proposition 5. Under (A1) and (A2), type-related information has strictly negative value if the equilibrium in the hidden information case exhibits positive effort levels.

The proof of this proposition follows from the fact that if the seller exerts no effort in the equilibrium of the hidden information case, then the two cases yield the same welfare to the buyer (because the participation constraint of the $\theta_{H}$-seller is binding in both cases). Consider now an optimal contract $\left\{p_{1}^{*}, T^{*}\right\}$ which induces effort in the hidden information case. Clearly, this contract must be superior to any other contract, including those under which the seller exerts no effort. Thus the buyer must be better-off by being ignorant of the seller's type.

(A1) and (A2) and our assumptions on the utility functions of the two parties are quite restrictive, but keep the analysis simple and clear. We can easily identify two main factors behind the result in Proposition 5. The first is noncontractibility of quality. If quality were contractible, the seller could be induced to choose the efficient level of effort, hence type-related information could not have a negative value. The second factor is the interaction between two hidden types and noncontractibility of quality, as a result of which the use of effort in signaling the type creates the potential for enhancing the buyer's welfare. But this effect vanishes when the seller's type is common knowledge. ${ }^{14}$

14 There is a direct analogy between the seller's choice of effort in our model and workers' choice of speed in Akerlof's (1976) "rat race,' managers' choice of effort in Holmstrom (1982) and Gibbons and Murphy (1992). The efficiency consequences of our model differ from the latter three, however. Efficiency obtains in Akerlof's model in the absence of race, in Holmstrom's in the absence of career concerns whereas here the seller exerts no effort under equivalent conditions. The inclusion of hidden information in our model puts the seller in a rat-race situation and leads to positive effort levels. Although the buyer 
An interesting implication of Proposition 5 is in the context of organizational design. It has been argued that ignoring credentials in promotion decisions actually eliminates a real cost for the organization, the cost arising from what Milgrom (1988) calls "influence activities." Proposition 5 suggests additional gains: ignoring credentials (some of which are type-related information) will not only lead candidates to reallocate their efforts to productive uses, but also to a further increase in performance due to the competition between types, despite the incompleteness of contracts. The idea is a familiar one in game theory: in order to induce others (seller-types) to play in a desirable way, a player (the buyer) may actually gain from limiting her own information if others know she has done so.

\section{COMMITMENT}

A variant of the governance structure studied in Section 4 allows commitments to verifiable variables (prices and durations) beyond the actual period. We denote the corresponding long-term contract by $C_{L}=\left\{p_{1}, T, p_{2}\right\}$ and allow this contract to include a clause authorizing the buyer to decide upon the continuation of the relationship at date $T$ (she is free to keep the seller $(b=1)$ or switch $(b=0))$. This clause gives a best chance to the commitment about $p_{2}$ though we shall point out the case where it becomes effective. Because commitments for verifiable variables are enforceable and the parties' objectives conflict, any proposal to modify $p_{2}$ at date $T$ will be vetoed either by the buyer or the seller, so there is no room for $p_{2}$ being renegotiated. ${ }^{15}$ Then, continuation at the specified price $p_{2}$ brings forth the expected discounted utility $V\left(p_{2}, \mu\right)=\left(\mu \theta_{H}+(1-\mu) \theta_{L}-p_{2}\right) / r$ to the buyer. So the optimal long-term contract $\left\{p_{1}^{c}, T^{c}, p_{2}^{c}\right\}$ solves

$$
\max _{\left\{p_{1}, T, p_{2}\right\}} E\left[\frac{\left(1-e^{-r T}\right)}{r}\left[\theta+x-p_{1}\right]+e^{-r T} \max \left\{V^{0}, V\left(p_{2}, \mu\right)\right\}\right]
$$

subject to (4') and (5'), to the fact that the seller determines $x$ through (7), and that $\mu$ be obtained through the Bayes' rule. Note that the dynamics of prices, $p_{1} \leq p \leq$ $p_{2}$, must hold. But because $p_{2}$ is fixed, the continuous link between the seller's effort and $p_{2}$ disappears: provided that effort is high enough to convince the buyer for the continuation of the relationship, the seller will obtain the prespecified price $p_{2}$ from date $T$ on. Although we shall not characterize in detail optimal long-term contracts (there are many), we note that with the slight modification mentioned above, the solution concept used in the noncommitment case applies here as well.

We shall classify long-term contracts according to the buyer's posterior $\mu$ at the interim date $T$. Given $p_{2}$, Figure 5 visualizes the classification of potential outcomes. The critical level of posterior, $\mu^{c}$, is defined by $V\left(p_{2}, \mu^{c}\right)=V^{0}$, so that the buyer sets $b=1$ if $\mu \geq \mu^{c}$ and $b=0$ otherwise. Let us start with region-I, characterized by the pairs $\left\{p_{1}, T\right\}$ that yield $\mu=1$; only the $\theta_{H}$-seller accepts the

almost never obtains the efficient level of effort, the resulting quality is a net improvement upon the quality she obtains under perfect information.

15 This is generally not true, if for example parties have different discount rates and commitments for at least one period ahead are possible (see Rey and Salanie 1990). 


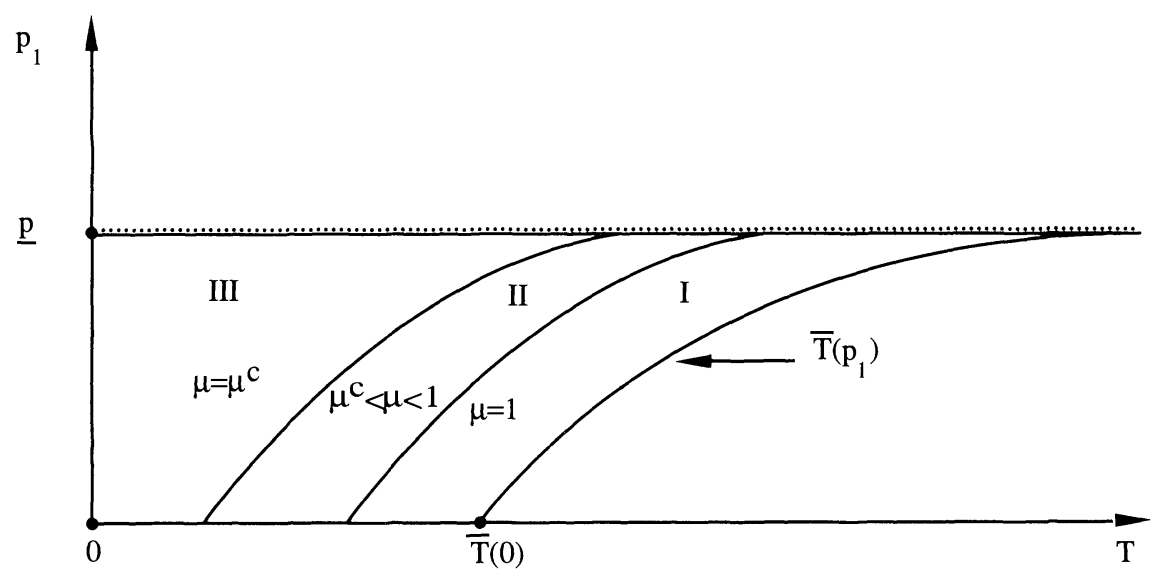

Figure 5

contract and exerts no extra effort $\left(x_{\theta_{H}}=0\right)$, so $q=\theta_{H}$. The southeastern border of region-I is the $\bar{T}\left(p_{1}\right)$ locus which defines the maximum duration of the first period as a function of $p_{1}$. Thus the $\bar{T}\left(p_{1}\right)$ locus in Figure 5 coincides with that in Figure 4 if $p_{2}$ is specified at the level that would be determined through negotiations, i.e., when $p_{2}=p_{2}^{*}(1)$. To the northwest lies region-II, the set of pairs $\left\{p_{1}, T\right\}$ that yield a continuum of posteriors $\mu \in\left[\mu^{c}, 1\right)$. Again, the $\theta_{H}$-seller accepts the contract and puts $x_{\theta_{H}}=0$, but the $\theta_{L}$-seller may also accept and find it worthwhile exerting an effort just enough to mimic the $\theta_{H}$-seller. This too yields $q=\theta_{H}$ during the first period $[0, T)$. Because $p_{1}<p_{2}$ and quality is constant throughout region-I and II, it is optimal for the buyer to choose the highest possible $T$. Doing so, the buyer obtains the same quality, pays a low price for a longer period and increases her expected welfare from the second period. We can thus eliminate region-I and II, both dominated by the $\bar{T}\left(p_{1}\right)$ locus.

Finally, region-III, the northwestern neighbor of region-II, represents the set of $\left\{p_{1}, T\right\}$ that yield all the same posterior $\mu^{c}$. The clause authorizing the buyer to decide upon the continuation of the relationship becomes effective here. It guarantees a minimum quality $q=\theta_{H}$ to the buyer for the period $[0, T)$. If $p_{1}$ is increased and/or $T$ is reduced, the $\theta_{H}$-seller increases effort just enough to systematically leave the buyer indifferent between continuation and termination. With respect to the dependence of quality on $\left\{p_{1}, T\right\}$ in region-III, Proposition 3 applies. Here the buyer has a weaker incentive to choose $\mathrm{p}_{1}$ and $T$ in region-III than in the noncommitment case because the seller keeps effort low at a level that yields the constant posterior $\mu^{c}$, where $\mu^{*}=1$ guarantees higher effort levels in the noncommitment case.

As the foregoing discussion shows, to prespecify $p_{2}$ is not beneficial for the buyer. This reproduces the principle of negative protection (Farrell and Shapiro 1989): generally, an incomplete but long-term contract decreases the buyer's protection against opportunism. This result holds except trivially when the relevant variables are chosen at levels that would have been chosen under noncommitment (that is, if $p_{2}=p_{2}^{*}(1)$ and $\left\{p_{1}, T\right\} \in \bar{T}\left(p_{1}\right)$ ). 


\section{CONCLUDING REMARKS}

This paper explores the thesis that learning about innate values plays an important role in the choice of governance structures, investigates how instrumental the terms of sequential contracts are in this learning process, and provides insights on the number of contracts and the value of type-related information in a continuous-time framework with noncontractible quality. In this section, we highlight questions raised by the analysis and extensions for future research.

An important unsettled issue is the explanation of the number of contracts in relation to the nature of relationships. The question of why the number of contracts we observe have a special tendency to be small can be answered in terms of renegotiation costs, but this would hardly be the whole story. On this, we show that more than two contracts is redundant when the buyer's target is the seller with the highest innate value, thus screening considerations play a role in restricting the number of contracts. This analysis awaits an extension to the more general case in which many seller-types are valuable from the buyer's perspective. For example, such an extension promises a dynamic theory of hierarchies in large organizations where labor input is highly specific. Determining the optimal number of contracts with endogenous durations and prices for this general case appears to be a very difficult task, however. The feasibility of a sequence of two contracts nevertheless extends to the case where $m$ out of $n$ innate values are desirable. The buyer can offer a menu of $m$ initial contracts with different prices and durations, each tailored for one innate value, or even a single initial contract under which in equilibrium $m$ innate values provide $m$ different qualities. The terms of the second contract would then be negotiated under perfect information. An alternative contractual arrangement is sequential screening, by which we mean a gradual resolution of typeuncertainty. Each contract would screen the lowest desirable innate value, all others would go through the next contract. This contractual arrangement yields $m+1$ as the maximum number of contracts with $m$ desirable innate values. The optimal number of contracts should therefore lie in between two and $m+1$, but this conjecture remains to be proved.

An interesting question that arises is which contractual arrangement achieves an efficient matching between buyer and seller types when quality is not contractible. To deal with this problem, the model should be extended to allow for many quality dimensions (in this paper we have only one.) The possible types of the buyer and the seller, as well as the preferences of each type should be defined on this quality space. In the case of labor services, the quality dimensions may include speed, creativeness, work discipline, cooperativeness, or any other job-specific ability. The complication arises from the fact that the terms of the proposed contracts will convey information about the buyer's type. Thus, relationships involve learning on both sides, and the buyer too may act strategically and conceal her type. However, if we have an equilibrium where buyer types separate, the problem reduces to the one analyzed in this paper, as a consequence more than two contracts for the relationship is redundant. The seller will exert an effort sufficient to eliminate the possibility of being imitated by the "neighbor" types, and matching will obtain at 
the end of the first contract. Derivation of conditions under which buyer types separate is a key issue, but this should be analyzed in an extended model.

The question of how the interactions between multidimensional hidden knowledge, external uncertainty and the relationship-specificity of assets affect the parties' welfare and the choice of governance structures awaits being addressed in an incomplete contracts setting. It is quite possible that standard results obtained under complete contracts will be upset, as exemplified by our result on the value of type-related information and Farrell and Shapiro's (1989) principle of negative protection. The key factors behind the result that the buyer may benefit from the hidden information "problem" are noncontractible quality (contract incompleteness) and the screening process through which the seller conveys type information. Given that quality is not contractible, competition between seller types to signal a high innate value provides incentives to exert effort, whereas under complete information this incentive effect disappears. Because hidden information about abilities is a common phenomenon in the beginning of relationships, the fact that young employees are more productive can be explained in terms of the screening process and career concerns. And the high performance generated by the screening process may make employers better-off under hidden information.

The use of a continuous-time framework has allowed us to show the importance of time as a screening device, which underlies as well most of the results derived in models of strikes and bargaining under incomplete information. Regarding the link between prices, durations and quality, the analysis identifies a trade-off. Decreasing the duration of a probationary contract brings the critical continuation decision forward in time, and given the expected value of continuation, the seller enjoys avoiding some discounting, which in turn increases the competition between seller types. The result is higher effort and quality for the buyer. But the improvement in quality must be high enough to offset the cost of decreasing the duration, which is balanced by the optimal first contract. This trade-off provides an explanation for differential durations of probationary contracts as a function of the importance of screening considerations.

Bilkent University, Turkey

\section{REFERENCES}

Akerlof, G., "The Economics of Caste and of the Rat Race and Other Woeful Tales,' Quarterly Journal of Economics 90 (1976), 599-617.

Alchian, A. And H. Demsetz, "Production, Information Costs, and Economic Organization," American Economic Review 62 (1972), 777-795.

Crawford, V., "Long-term Relationships Governed by Short-term Contracts," American Economic Review 78 (1988), 485-499.

DyE, R., “'Optimal Length of Labor Contracts," International Economic Review 26 (1985), 251-270.

FARRELl, J. AND M. SHAPIRO, “Optimal Contracts with Lock-in,” American Economic Review 79 (1989), $51-68$.

Fudenberg, D., B. Holmstrom and P. Milgrom, "Short-term Contracts and Long-term Agency Relationships," Journal of Economic Theory 52 (1990), 194-206.

Grbbons, R. AND K. J. Murphy, "Optimal Incentive Contracts in the Presence of Career Concerns: Theory and Evidence," Journal of Political Economy 100 (1992), 468-505. 
Harris, M. AND B. Holmstrom, “On the Duration of Agreements," International Economic Review 28 (1987), 389-405.

Hart, O. and B. Holmstrom, "The Theory of Contracts," in T. Bewley, ed., Advances in Economic Theory: Fifth World Congress (Cambridge: Cambridge University Press, 1987).

AND J. Moore, "Incomplete Contracts and Renegotiations,"' Econometrica 56 (1988), 755-785.

Holmstrom, B., 'Managerial Incentive Problems-A Dynamic Perspective,'” in B. Walross, ed., Essays in Economics and Management in Honor of Lars Wahlbeck (Helsinki: Swedish School of Economics, 1982).

- AND P. Milgrom, "Aggregation and Linearity in the Provision of Intertemporal Incentives," Econometrica 55 (1987), 303-328.

Laffont, J. J. and J. TiRole, "Using Cost Observation to Regulate Firms," Journal of Political Economy 94 (1986), 614-641.

MacLeod, B. ANd J. M. Malcomson, "Reputation and Hierarchy in Dynamic Models of Employment," Journal of Political Economy 96 (1988), 832-854.

MCAFEe, P. AND J. MCMILlan, "Competition for Agency Contracts," Rand Journal of Economics 18 (1987), 296-307.

Milgrom, P., "Employment Contracts, Influence Activities, and Efficient Organization Design,' Journal of Political Economy 96 (1988), 42-60.

Rey, P. And B. Salanie, "Long-term, Short-term and Renegotiations: On the Value of Commitment in Contracting," Econometrica 58 (1990), 597-619.

Shapiro, C. AND J. E. Stiglitz, “Equilibrium Unemployment as a Worker Discipline Device,” American Economic Review 74 (1985), 433-444.

Townsend, R. M., “Optimal Multiperiod Contracts and the Gain from Enduring Relationships under Private Information," Journal of Political Economy 90 (1982), 1166-1186.

Williamson, O., The Economic Institutions of Capitalism (New York: The Free Press, 1985). 